\title{
Yield Loss and Economic Threshold Level of Soybean due to Leaf Roller (Apoderus cyaneus Hope) in Nepal
}

\author{
Bishnu K Gyawali* \\ Entomology Division-NARC, Khumaltar-Lalitpur-Nepal
}

\begin{abstract}
Yield loss in soybean due to leaf roller (Apoderus cyaneus Hope) was studied at Khumaltar during 1985 and 1986 seasons. Field experiments were conducted during vegetative as well as reproductive stages of soybean. Rolled leaves of soybean with eggs, grubs and pupae were collected from the field and reared in the laboratory for adults. Adults were introduced into nylon cages installed at the central rows of each plot just after germination of soybean. Insects were maintained at population density of 25,50 and 100 per $\mathrm{m}^{2}$. At maximum (100) adult density, the potential grain yield loss of cultivar, Ransom soybean in its vegetative and reproductive stages were 103 and $48 \mathrm{mg}$ per day respectively from each adult of A. cyaneus. Percentages of yield losses were 36.2, 45.2, and 58.0 during vegetative and 37.5, 48.5 and 66.0 during reproductive stages from the insect population of 25,50 and 100, respectively which, was not in accordance with the level of two and four fold increased population density of insect. Yield reduction was higher ( 260 and $108 \mathrm{mg}$ per day) from each adult beetle at lower population level (25) in both vegetative and reproductive stages of soybean.
\end{abstract}

Key words: Economic threshold level, leaf roller, physiological growth stages, yield loss

\section{INTRODUCTION}

Soybean occupies 21245 ha and average yield is only $731 \mathrm{~kg} / \mathrm{ha}$ (ASD 1999). The potential yield of cultivar, Ransom is $3.79 \mathrm{t} / \mathrm{ha}$. The country's average yield is very low due to several factors and one of them is invasion of insect pests. Pre-harvest loss from insect pests has not been estimated, but damage was observed and reported (Gyawali 1982, 1986). The yield loss from the leaf roller (Apoderous cyaneus Hope) was not previously studied in Nepal and has not been reported anywhere in the world. The threshold estimate is the population level that would cause damage equal to the cost of control at a given application rate of pesticide. It was assumed that the use of an insecticide at the given rate would prevent the yield loss.

The objectives of this study were (i) to establish a relationship between insect population density and yield loss in vegetative and reproductive stages of the soybean plant, and (ii) to determine the economic threshold levels of A. cyaneus in both the physiological stages of the crop.

\section{MATERIALS AND METHODS}

The $\mathrm{pH}$ of the experimental plot ranged from 5.44 to 5.52 and 5.26 to 5.36 for vegetative and reproductive stages respectively. A basal dose of chemical fertilizers $(20: 20: 40 \mathrm{~kg} / \mathrm{ha}$ NPK) was incorporated into the soil at the time of seeding (3 June 1985). Similarly, in 1986 seeding was done on

\footnotetext{
${ }^{*}$ Current address: 3 Ka/471 Pulchowk, PO Box 122, Lalitpur-Nepal. <nbc@bkg.wlink.com.np>
} 
17 June for the vegetative stage and on 18 June for the reproductive stage. Seeds germinated on 9 June 1985 and 23 and 24 June 1986 for vegetative and reproductive stages, respectively. The plot size used was $4-\times 3-\mathrm{m}$. There were five replications per treatment. Row to row and plant to plant spacing was 50 and $5 \mathrm{~cm}$ respectively. A cage measuring $32 \mathrm{~cm}$ in diameter and $1 \mathrm{~m}$ in height was installed at the center of $4 \mathrm{~m}$ long row just after germination of soybean. Each cage occupied an area of $804 \mathrm{~cm}^{2}$. Four vertical wires (each $80 \mathrm{~cm}$ long) and three circular galvanized wires of 14 gauze were used to hold the cage upright. At each intersection, fine wires were used to tighten the others. One-meter long 40-mesh nylon was used to cover the wire framework and thread was used to stitch the nylon mesh. Both ends of the cage were open at the upper end having 20-cm long sleeve. A thick-waxed thread was used to close the upper end in order to trap caged insects. No extraneous insect feeding was allowed other than test insects.

Rolled leaves of soybean with eggs, grubs and pupae of A. cyaneus were collected from the field and reared in the laboratory for adults. Adult insects of both sexes were introduced into the cages with a density of $0,2,4$ and 8 per cage $\left(0,25,50\right.$, and $\left.100 / \mathrm{m}^{2}\right)$ for both the vegetative and reproductive stages. Insects were checked on alternate days and the dead ones were replaced by reared stock. A control cage with no insects was also maintained in vegetative and reproductive stages of soybean.

Separate statistical analysis was carried out for vegetative and reproductive stages. Stages of development for soybean were followed according to the criteria identified by Fehr and Caviness (1977) and reported by Gyawali (1988).

Adults of A. cyaneus were introduced on 7 July at V4 stage and removed from the cages on 26 July in 1985 at V6 stage. In case of 1986 beetles were introduced on 18 July at V3 stage and removed on 6 August at V5 stage. The duration of feeding was the same (18 days) for both the years.

A. cyaneus was introduced on 26 July at R2 stage and removed from the cages on 26 Sept in 1985 at R7 stage. In case of 1986, it was introduced on 5 August at R1 stage and removed on 6 October at R7 stage. Feeding duration was 61 days for both the years.

Computational procedures for economical threshold level (ETL) have been based on Liapis et al (1984) and Gyawali (1985). The damage and yield loss relationship together with information on the price of soybean and the cost as well as effectiveness of control measures were used to imply treatments for insect species for a given period. This was done for situation where statistical analysis suggested susceptibility of soybean to become damaged. Solving the following equation derived the threshold population: $\mathrm{P}-\mathrm{Y}$. $\mathrm{X}-\mathrm{I}-\mathrm{A}=0$

Where, $\mathrm{P}$ is soybean price, $\mathrm{Y}$ is yield loss due to insect pest at population $\mathrm{X}, \mathrm{I}$ is the cost of insecticide, $\mathrm{A}$ is the application cost and $\mathrm{X}$ is the threshold population measured at density per unit of land.

The market price of soybean was estimated from 1987 to 1999 as Rupees per kilogram. Cost of insecticide (Endosulfan) was also estimated as Rupees/liter. This was averaged for the two vegetative and reproductive stages of soybean. Application costs were based on Rupees/hour.

\section{RESULTS AND DISCUSSION}

The mean grain yield of Ransom soybean in control cage produced significantly more yield than infested cages at vegetative and reproductive stages (Table 1). A. cyaneus introduced on vegetative and reproductive stages with a population densities of 2 insects per cage produced significantly more yield than at population density of 8 insects per cage. 
Table 1. Mean grain yield (g) and yield loss of Ransom soybean at vegetative and reproductive stages due to feeding of adults of $A$. cyaneus, combined data for wet- season (upland) of 1985 and 1986 Khumaltar

\begin{tabular}{|c|c|c|c|c|c|c|c|c|}
\hline \multirow[t]{2}{*}{ Crop stage } & \multirow{2}{*}{$\begin{array}{l}\text { Feeding } \\
\text { duration, } \\
\text { days }\end{array}$} & \multicolumn{4}{|c|}{$\begin{array}{l}\text { Population density of A. cyaneus adults per } \\
\text { cage }\end{array}$} & \multicolumn{3}{|c|}{ Yield loss per cage } \\
\hline & & 0 & 2 & 4 & 8 & 2 & 4 & 8 \\
\hline Vegetative & 18 & $25.8 \mathrm{a}$ & $16.5 b$ & $14.2 \mathrm{bc}$ & $10.9 \mathrm{c}$ & 9.34 & 11.6 & 14.9 \\
\hline Reproductive & 61 & $35.3 \mathrm{a}$ & $22.1 \mathrm{~b}$ & $18.2 \mathrm{~b}$ & $12.0 \mathrm{c}$ & 13.2 & 17.1 & 23.3 \\
\hline
\end{tabular}

Means in a row followed by the same letter are not significantly different at the 5\% level by Duncan's Multiple Range Test.

Mean grain yield loss of Ransom soybean due to infestation of A. cyaneus at a population density of $100 / \mathrm{m}^{2}$ showed significantly more than densities at 25 in vegetative and at 50 and 25 population densities in the reproductive stage (Table 2).

Table 2. Mean grain yield loss ( $\mathrm{g}$ and $\%$ ) from $\mathbf{A}$. cyaneus adults during_vegetative and reproductive stages of Ransom, combined data for wet- season (upland) of 1985 and 1986 Khumaltar

\begin{tabular}{lccrc}
\hline Crop stage & Feeding & \multicolumn{3}{c}{ Population density per $\mathrm{m}^{2}$} \\
\cline { 3 - 5 } & duration, days & 25 & 50 & 100 \\
\hline Vegetative & 18 & $117.0 \mathrm{~b}(36.2 \%)$ & $146.1 \mathrm{ab}(45.9 \%)$ & $187.3 \mathrm{a}(58.0 \%)$ \\
Reproductive & 61 & $165.6 \mathrm{c}(37.5 \%)$ & $214.1 \mathrm{~b}(48.5 \%)$ & $291.4 \mathrm{a}(66.0 \%)$ \\
\hline
\end{tabular}

Means in a row followed by the same letter are not significantly different at the 5\% level by Duncan's Multiple Range Test.

A. cyaneus tested on the vegetative stage with a population density at $25 / \mathrm{m}^{2}$ produced the mean grain yield loss of $117.0 \mathrm{~g} / \mathrm{m}^{2}$. On the other hand, the same insect at a population density of $50 / \mathrm{m}^{2}$ caused $146.1 \mathrm{~g}$ yield loss. Also, the same insect at a population density of $100 / \mathrm{m}^{2}$ produced $187.3 \mathrm{~g}$ yield loss. When A. cyaneus was tested on reproductive stage at 25 populations density $/ \mathrm{m}^{2}$ produced $165.6 \mathrm{~g}$ yield loss. The same insect at population densities of $50 / \mathrm{m}^{2}$ caused $214.1 \mathrm{~g}$ yield loss. Similarly, the same insect at population densities of $100 / \mathrm{m}^{2}$ made $291.4 \mathrm{~g}$ yield loss.

Mean grain yield loss from A. cyaneus was more than $260 \mathrm{mg}$ per insect per day at lower population density ( 2 per cage or $25 / \mathrm{m}^{2}$ ) than at higher level of crowding (4 per cage or $50 / \mathrm{m}^{2}$ and 8 per cage or $\left.100 / \mathrm{m}^{2}\right) 162$ and $103 \mathrm{mg}$ per insect per day in vegetative stage (Table 3). Similarly, in reproductive stage of Ransom soybean, the loss was more than $108 \mathrm{mg}$ per insect per day at lower population density $\left(2\right.$ per cage or $25 / \mathrm{m}^{2}$ ) than at higher density (4 per cage or $50 / \mathrm{m}^{2}$ and 8 per cage or $100 / \mathrm{m}^{2}$ ) 70 and 48 mg per insect per day.

Table 3. Mean grain yield loss (mg) of Ransom soybean per day per A. cyaneus adult during vegetative and reproductive stages during 1985 and 1986

\begin{tabular}{lllllll}
\hline Crop stage & \multicolumn{3}{c}{ Population density } & \multicolumn{2}{c}{ Compensation } \\
\cline { 2 - 7 } & 25 & 50 & 100 & Loss & 2 fold loss & 4 fold loss \\
Vegetative & 260 & 162 & 103 & 260 & $520-162=358$ & $1040-103=937$ \\
Reproductive & 108 & 70 & 48 & 108 & $216-70=146$ & $432-48=384$ \\
\hline
\end{tabular}

The yield loss was much higher in vegetative stage than in reproductive stage for the same population densities, 2 per cage or 25 insects $/ \mathrm{m}^{2}$. This could be because the vegetative stage is more susceptible than the reproductive stage. Or compensation was initiated to 358 and $937 \mathrm{mg}$ per day per individual as the population increased from 2 per cage or 25 to 4 per cage or 50 and 8 per cage or $100 / \mathrm{m}^{2}$ densities in vegetative stage of Ransom soybean. Similarly, in reproductive stage of soybean the compensation was initiated to 146 and $384 \mathrm{mg}$ per day per insect as the population increased from ( 2 per cage) 25 to (4 per cage) 50 and (8 per cage) 100 densities, respectively. In other words compensation by the Ransom 
soybean in vegetative stage is much higher than the reproductive stage. Environmental interaction between cultivar and the location might have played a significant role in compensation or possibly there is a relationship between population density and the magnitude of compensation by the $\mathrm{cv}$ Ransom as well as the physiological stages of soybean. As the population density increases compensation by the plant also seems to be increase. As the percentage of loss was increased, the yield loss was also found to increase.

The economic threshold level (ETL) of A. cyaneus for vegetative and reproductive stages is given in (Table 4). It is necessary to decide at which population density the pests have to be controlled. When the population density reaches the quantified numbers $(2$ and 1$)$ in vegetative and $(7,6,5$, and 4$)$ in reproductive stages in the corresponding years as shown in Table 2 helps the farmer not to apply chemical insecticides for control of this insect when the population is lower (eg 9 insects $/ 10 \mathrm{~m}^{2}$ ).

Table 4. Economic threshold level (ETL) of A. cyaneus for a period of thirteen years in vegetative and reproductive stages of Ransom soybean 1999 Khumaltar

\begin{tabular}{lcc}
\hline Year & \multicolumn{2}{c}{ Population density per $\mathrm{m}^{2}$} \\
\cline { 2 - 3 } & Vegetative stage & Reproductive stage \\
\hline 1987 & 2 & 6 \\
1988 & 2 & 7 \\
1989 & 2 & 6 \\
1990 & 1 & 5 \\
1991 & 1 & 5 \\
1992 & 1 & 4 \\
1993 & 1 & 4 \\
1994 & 1 & 5 \\
1995 & 1 & 4 \\
1996 & 1 & 4 \\
1997 & 1 & 4 \\
1998 & 1 & 4 \\
1999 & 1 & 4 \\
2000 & 1 & 4 \\
2001 & 1 & 4 \\
2002 & 1 & 4 \\
2003 & 1 & 4 \\
2004 & 1 & 4 \\
\hline
\end{tabular}

Increased insect population density caused more yield loss but the proportionate increase in insect population did not show proportionate loss. The insect caused more yield loss in reproductive stage than in vegetative stage but the yield loss per insect per day was higher in vegetative stage than reproductive stage. This might be due to compensation of the plants to the increased level of insect population.

\section{ACKNOWLEDGEMENTS}

Sincere appreciation is extended to the Agronomy Division for the support of labour cost, Plant Pathology Division for providing experimental land and Seed Technology and Seed Improvement Program of Nepal Agricultural Research Council for determining moisture percentage by oven method. Appreciation is expressed to D Neupane, Entomology Division for field and laboratory help. A. cyaneus is a new species of soybean insects pests in Nepal and was identified by CAB International Institute of Entomology, British Museum (Natural History) UK through the courtesy of G Garrod of Lumle Agricultural Research Centre who paid the cost to the British Museum. 


\section{REFERENCES}

ASD. 1999. Area production and productivity of food legumes. In: Agricultural Statistics of Nepal 1998/99. Agricultural Statistics Division-Ministry of Agriculture, HMGN, Singha Durbar-Kathmandu-Nepal. 110p.

Fehr WR and CE Caviness. 1977. Stages of soybean development. Agri. Home Econ. Exp Station. Iowa State University. Special Rep. 80:11 p.

Gyawali BK. 1982. Population dynamics of soybean insects. J. Nat. Hist. Mus. 6(4):101-109.

Gyawali BK. 1986. The insect complex in the soybean agro-ecosystem at Khumaltar in Kathmandu valley, Nepal. Tropical Pest Management 34(4):327-332.

Gyawali BK. 1988. Yield loss from insect complex at different growth stages of soybean. In: Proceedings Ist National Conference on Science and Technology, 24-29 April 1988, Kathmandu-Nepal. Pp. 90-100.

Liapis PS, LJ Moffitt and EG King. 1984. Heliothis spp. (Lepidoptera: Noctuidae) damage and yield loss estimated from commercial cotton field. J. Econ. Entomol. 77(3):798-801. 